considerations are put forward which add further weight to the author's views.

In a series of tics or stereotypies, the secondary if not the chicf function is to draw attention and feeling from time to time towards particular parts of the body. In some cases tic is the outcome of constitutional narcissism ; in others, the 'pathoneurotic tics', it arises as a result of an injury of a part of the body already heavily charged with libido (an erotogenic zone). Ferenczi would add what he calls the 'ego-memory system' to Freud's scheme of the building up of the 'psychical systems'. To this system falls the task of continually registering the subject's own mental processes. It would have a stronger development in a constitutional narcissist than in people of completely developed object-love.

To explain the formation of tic, a conflict inside the ego (between the cgo-nucleus and narcissism) and a process analogous to repression must be supposed. The writer traces back the origin of tic to an increase of narcissism in the following manner: "In the case of 'patho-neurotictic tic', the injured or stimulated part of the body (or its psychic representative) is charged with excessive interest and libido. The quantity of energy required for this is drawn from the greatest libido rescrvoir, the genital sexuality, and this must of necessity be accompanied by a decrease of potency in the normal genital sensations. This results in a displacement of not only a certain quantity of energy from below upwards, but also a displacement of quality (innervation-character); hence the 'genitalization' of the parts affected by tic (excitability, tendency to rhythmical rubbing, in many cases definite orgasm). In cases of tic of 'constitutional narcissists' the primacy of the genital zone generally appears to be not quite firmly established, so that even ordinary stimuli or unavoidable disturbances result in a similar displacement."

The hysteric conversion symptoms are expressions of (genital) object love, clothed in the form of auto-erotism, while the tics and catatonia are auto-erotism which has to some extent adopted genital qualities.

\title{
C. IV. Forsyth.
}

\section{PSYCHOPATHOLOGY.}

[1+3] Disorders of symbolic thinking due to local lesions of the brain. -R. Mourgue. Brit. Jour. Psychol. (Med. Sect.), 1921, i, 97.

'TuIs paper should be read in conjunction with the recent researches of Head. The author accepts the general principles laid down by Hughlings Jackson, and is largely, though not entirely, in agreement with Head's conclusions. Mourgue views the phenomena termed aphasia from a broad standpoint, and finds the fundamental trouble to be a loss of the 'function de découpage et d'opposition de l'intelligence'-discrimination and differentiation. Everything takes place as if the thoughts of the aphasic presented themselves sometimes as an undifferentiated mass, at others as isolated units. In either case all 'opposition' is impossible, and this allows more primitive instinctive reactions to reassert themselves. Intelligence and language are closely associated ('coulés dans le même moule'), 
but in aphasia due to circumscribed lesions, vast. regions of thought and instinctive mechanisms remain intact-even experience an increased activity-while higher integrative functions upon which symbolic thinking and language depend are interfered with.

Mourgue supports his thesis by reference to the autobiographical memoirs of aphasics, especially those of Dr. Saloz and Professor Forel ; also by a comparative study of a highly developed modern language (French) with Chinese, citing for this purpose the recent work of Granet (Quelque particularités de la langue et de la pensée chinoises).

Alfred Carver.

"A child is being beaten." A contribution to the study of the origin of sexual perversions. Sigmund Freun. Internat. Jour. of Psycho-analysis, 1920, iv, 371.

A Number of people suffering from hysteria or an obsessional neurosis have experienced the phantasy: "A child is being beaten". It has feelings of pleasure attached to it, and at the climax of the imaginary situation there is almost invariably an onanistic gratification. Analysis brings out certain differences in the origin of the phantasy in the two sexes. In this abstract its origin in the female sex is alone dealt with. The first phantasies were entertained very early in life, before school age. The phantasy of beating goes through three phases. In the first phase the child being beaten is never the one producing the phantasy, but it is most often a brother or a sister. At first the person beating is an adult; later he becomes recognizable as the (girl's) father. The first phantasy is represented by the phase: "My father is beating the child whom I hate". The second phase-" I am being beaten by my father"-is the most important, although it has never succeeded in becoming conscious. It is a construction of analysis. The third phase resembles the first. The person beaten is never the father. Instead of one child being beaten, there are now a number of children present as a rule. In girls' phantasies it is usually boys who are being beaten. The first and third phases appear to be sadistic, whereas the second is undoubtedly of a masochistic nature.

Analysis shows that the affections of the child are 'fixed' upon her father. She dislikes the other children in the nurscry, as they share their parent's love. Being beaten signifies a deprivation of love and a humiliation. The beating means: "My father does not love this other child; he only loves me". The phantasy gratifies the child's jealousy, and is dependent upon the erotic side of its life, but it is powerfully reinforced by its egoistic interests. It is " not clearly sexual, not in itself sadistic, but yet the stuff from which both will later come". The sexual life of the child has reached the stage of genital organization now that the incestuous love has made this premature choice of an object. None of these incestuous loves can avoid the fate of repression, leaving a sense of guilt. This sense of guilt causes the phantasy to become masochistic-that of being beaten by the father. This is now not only the punishment for the forbidden sexual relation, but also the regressive substitute for it; and from this latter source it derives the libidinous excitement which is from 
this time forward attached to it, and which finds its outlet in onanistic acts. In the third phase, girls in turning away from their incestuous love for their father, with its genital significance, easily abandon their feminine rôle. They spur their 'masculine complex' into activity, and from that time forward only want to be boys. The persons now being beaten are boys who represent them.

Analysis of these cases aids in the discussion concerning the origin of the perversions. The view is confirmed that masochism is not the primary expression of an impulse, but has been turned round and directed against the ego under the influence of the sense of guilt concerned in the act of repression. Confirmation is also given to Freud's opinion that the Edipus complex is the nucleus of a neurosis, and the infantile sexuality which culminates in this complex is the true determinant of the neurosis. What remains of the complex in the unconscious represents the predisposition to the later development of neurosis in the adult. Effects upon the character can be detected which are directly derived from the unconscious setting of the second phase. People who harbour phantasies of this kind develop a special sensitiveness and irritability towards anyone whom they can put among the class of fathers. It is possible that the same phantasy is the basis of the querulous delusions of paranoia.

C. W. Forsyth.

[145] The psychopathology of puberty and adolescence. (The Morison Lectures for 1921 and The Second Maudsley Lecture.)- SIR $^{-}$ Frederick Mott. Jour. of Ment. Sci., 1921, lxvii, 278.

Briefly stated, the theme running through these lectures is the establishment of the biogenic view of the development of dementia precox and allied pre-pubcrtal and adolescent conditions, with the careful exposition of the changes demonstrable by histological examination in the reproductive organs and in the central nervous system which go to indicate a purely physiogenic as opposed to a purely psychogenic origin of dementia praccox.

Noting the frequent occurrence of mal-devclopment of the generative organs in cases of idiocy and imbecility, Sir Frederick Mott proceeds to consider the circumstances applying in the case of the adolescent. Here the inherent life force of the individual, which so far had been expended on purely developmental activities, is diverted into two entirely new channels : (1) Energy has to be supplied to effect the new psychic adaptations rendered necessary by the maturation of the sexual instinct; and (2) Energy is required to support the process of spermatogenesis or ovogenesis which now comes into operation.

From these premises it is argued that, could demonstrable changes indicative of failure of function or of regression be found in the neural elements underlying the highest associational activities of the mind, i.c., in the intercalary neurones of the cortex, and also in the organs of reproduction, then there would be good grounds for regarding dementia pracox as essentially a condition arising from failure of the inherent vital energy, or, in other words, as a condition due to an inborn germinal defect.

With regard to (1), the author demonstrates that in cases of dementia 
pracox there is a parenchymatous degencration of the neurones, strikingly affecting the ccll-bodies as opposed to the fibres, and particularly marked in the granule layers of the cortex. In the earlier cases of the disorder the lesion is restricted to the absence of the Nissl bodies which are normally to be seen in the stained nerve-cell, their place being taken by lipoid granules which appear in the stained specimen as vacuolations in the cell, the lipoid substance haring been extracted in the process of preparation of the slide. In more advanced cases the appearances of marked nuclear and cytoplasmic disintegration are found, and in others a disappearance of the nervous element altogether. Such changes in the neurone itself are strictly comparable to those seen in senile dementia or dementia paralytica; but in these latter the evidences of vascular and interstitial fibrotic developments are predominant, whereas in the case of dementia procex such developments are not present.

With regard to (2), Mott finds a definite regressive: atrophy occurring in the testes and the ovaries in dementia pracox. In the male, spermatogenesis largely ceases and such gonads as are formed are mal-developed, while in the female the ova do not mature. These findings are quite restricted to cases of dementia pracox, for cases of dementia paralytica show active $s_{i}$ ) crmatogenesis up to the final stages of the discase.

The biochemistry of the nerve-cell is discussed, and the conclusion is reached that "the failure of function in dementia pracox may be correlated with a failure of oxidation processes in the grey matter, owing to a deficiency of the vital energy of the nucleus, as shown by morphological and biochemical changes in the nucleus and a failure in the production of the substance which is the antecedent of the Nissl gramules." The actual relationship between the changes in the central nervous system and those in the generative organs is left open for the time, but it is pointed out that two hypotheses may be held. First, the two pathological conditions may be looked upon as co-existent and both dependent on some, as yet unknown; fundamental germinal defect. Secondly, regarding the generative organs as part of the general hormonopoietic system, it may be that the regressive changes in the generative organs with suppression, or at least diminution, of their normally produced internal secretion, may be the direct cause of the failure of the nervous function.

Thomas BeatoN.

[146] The parataxes: a study and analysis of certain border-line mental states.-T. V. Moore. Psycho-analytic Rev., 1921, viii, 252.

In psychiatric work the importance of understanding rather than of naming abnormal mental states is insisted on, though names have their value. T'o facilitate this the author offers this study, with appropriate names for conditions that every psychiatrist has met, but for which he has not had satisfactory diagnostic terms. Though new names should be used with reluctance, the term 'psychotaxis' serves to signify a variety of facts which have much in common and which have not hitherto been subsumed in any general schema of mental abilities. The root $\tau$ á $\xi_{\text {es }}$ (tropism) is to designate the tendency of the mind to adjust itself to pleasant and un- 
pleasant situations. The tendency to make use of and enjoy pleasant emotions could be termed a positive psychotaxis, whereas the opposite tendency to avoid unpleasant situations is to be found in the negative class. These reactions are almost reflex in character, though they may be reinforced by conscious voluntary action. The positive psychotaxes do not vary much, though they may become associated with very complex mental operations. The negative psychotaxes, though varied, may be brought under the headings of (1) those that present no solution for the unpleasant situation, such as depression and anxicty; (2) those involving some kind of solution of the difficulty, however inadequate. With the latter there are three possibilities : (a) defence reactions ; $(b)$ compensatory reactions ; (c) sublimation. An attempt to meet the situation squarely is a voluntary effort under the influence of intellectual insight and ideals of conduct, and is not a psychotaxis. Any of the negative psychotaxes if carried to exeess may become pathological, and are then termed by Moorc 'parataxes'. Just as the psychotaxes are related to instinctive and reflex reactions, so the parataxes may be considered as related to the psychoneuroses and the major psychoses.

The parataxis of depression is then discussed. Sadness is a natural emotion, but it is associated at times with an impulse to persevere in the sorrow, and though it would be wrong to look upon every tendency to maintain a state of depression as pathological, such normal tendencies are psychotaxes. Between them and the depressive form of manic-depressive insanity there are a number of conditions which block the individual's activities and are injurious to the normal mental development. Such are pathological, though to be distinguished from the psychoses. All these states shade into each other without any clear line of demarcation, but the question may be raised as to whether the parataxis of depression is not the root of the manic-depressive psychosis. Not every incident can call forth the tendency to remain sad; it must be one that profoundly affects the individual's hierarchy of desires. In every depression there are two factors - the native disposition as hereditary, organic condition, and the psychical factor. Treatment should consist in seeking the cause of the depression, analyzing the situation, reconstructing life's adaptations, and stimulating affective outlets.

The parataxis of anxiety, though having a constitutional factor, depends mainly on an apparently irreconcilable conflict between incompatible desires. Realizing the true reason for the condition is frequently sufficient to bring it to an end in cases that are not of long standing, but the fundamental cure consists in the solution of the dilemma. Examples of these parataxes of depression and anxiety are given and discussed.

\section{Stanford Read.}

[147] Two unusual cases of parasexuality (Ueber zwci ungewöhnliche Fälle von Parasexualität).--M. Krrschbaum. Zeits. f. d. g. Neurol. u. Psychiat., 1921 , lxiv, 136.

'TuE first case was that of a medical man, age 30, who came under treatment for morphinism. The second was that of a student, age 22, who 
while serving in the army in Flanders had neglected his correspondence with his relatives, had afterwards gone on the stage and won flattering press notices of his acting as a young hero and lover, and had then been lost sight of for some months, till one day he presented himself, coarsely dressed as a labourer, at the psychiatric clinic at Cologne; he was found to have scars of bilateral operation for cryptorchism; a brother stated that the patient had from childhood been untruthful, given to telling incredibly fantastic storics, and that another brother had committed suicide.

Of sexual perversion there is in neither case any evidence other than what the patients' own statements purport to furnish. The first patient, the medical man, said that he had never had heterosexual or homosexual intercourse, and had never masturbated, but that for some years he had been in the habit of secretly dressing himself in women's clothes, tying himself up in a constrained posture before a mirror, and so obtaining sexual gratification. The story the student told was that the sight of grimy labourers, and the thought of becoming one himself, produced in him a sexual excitement; that he had therefore desired to break from his family and become a labourer; that he had been obsessed with the idea that he was sexually imperfect; that he had several times had homosexual intercourse; that he was achieving success as an actor, and had formed an attachment to a young actress in his company, but that then his obsessions revived, so he disappeared from the stage, bought labourer's clothes, and -worked for some months at the docks at Hamburg; and that now, coming to Cologne to enlist in the French Foreign Legion, he had been taken ill with pains in the chest, had consulted a doctor, and on his advice had come to the clinic as stated.

In each case the perversion is associated with an experience alleged to have oscurred in childhood. The first patient said that one night, when he was little, his nightshirt was missing, so his mother put him into a lace-trimmed nightdress of his sister's ; this gave him feelings of pleasure. The student said that from his window, when he was a child, he looked out over a house of correction; he often watched the convicts at work, and weaved romantic stories about them.

Kirschbaum, after remarking that such patients' statements must be received critically, accepts the alleged childish experience of each, and regards it as decisive in shaping the perverse behaviour. But I note that in neither case is there any independent testimony relating to that experience, or indeed anything to show that that experience, if it occurred, was in any respect decisive. Such patients are tempted, like other folk, by current opinion and example, and often also by medical suggestion, to excuse their misbehaviour by connecting it with something that happened before they were old enough to be responsible. I note that the student sets forth his childish experience, not in his voluminous main statement, but as an appendix or afterthought, evoked perhaps by leading questions ; and that the other patient, a medical man intercsted in psychology, was exposed, like Kirschbaum himself, to suggestion from books in which childish impressions are declared to be important.

Sydney J. Cole. 
Acute epidemic psycho-encephalitis and the psychic disorders of acute encephalitis (called lethargic) (La psycho-encéphalite aigıë cpidémique et les troubles psychiques de l'encéphalite aiguë dite léthargique).-HesnaRD. L'Encéphale, 1920, xv, 443.

Tine association between such symptoms as sommolence and ocular palsies and those which are definitely psychical has been noted in the course of infectious conditions such as influenza and pneumonia, long before the more recently described syndrome at present known as lethargic encephalitis. There is noted at first slight incoherence, which becomes more pronounced. The patient feels ill, is anxious and restless. The pupils are cither dilated or contracted. There may be strabismus. In the more severe cases there is ptosis, and sometimes paralysis of the facial nerve. Along with these symptoms there is an increasing somnolence, gradually merging into coma. The symptoms noted by various observers are extremely multiplex: stupor, catatonia, muscular rigidity, mental confusion, delirium, disorientation, and hallucinations. In some cases the condition suggests general paralysis of the insane, because of the mental state, and also because of the disorder of speech and the mask-like facies. Certain patients have an expression of astonishment.

The varicty of the symptoms supports the contention of Cruchet that there is a very diffuse infection of the cerebrospinal axis of an epidemic nature, which shows itself in the different forms described as convulsive, myoclonic, chronic, poliomyelitic, neuritic, etc. The name suggested for. this syndrome is diffuse cpidemic encephalomyclitis.

Hesnard divides cases showing mental symptoms into two classes: one where there are psychic symptoms in association with the classic type of encephalitis and with the others mentioned, and a sccond which he designates psycho-encephalitis. The latter he subdivides into:-

1. A psycho-somnolent variety where there supervene upon the ordinary symptoms of the encephalitis excitement, hypomania, confusion, followed by definite depression. The obscuration of consciousness may even suggest dementia.

2. Catatonic stupor without confusion but with uncxpected mental lucidity considering their general appearance and bchaviour. A curious symptom is observed in thesc cases. Muscular actions which have been commeneed, such as chewing, stretching out the hand, putting out the tongue, etc., are arrested midway, comparable with the condition of the Slecping Beauty and her entourage. This is due to an instinctive repugnance to effort-a kind of exhaustion of voluntary effort.

3. Acute delirium with great restlessness, hallucinations, incoherence, noisiness, and stercotyped movements. Pulse rapid, tongue dry; exaggeration or inequality of the reflexes. The prognosis in this variety is very grave.

4. Confusional type resembling the ordinary cases of confusion of a toxic character, with, chicfly, mental torpor.

5. Cases exhibiting the Korsakow syndrome, with disorientation, impairment of the memory, etc. This occurs only in those subject to 
prolonged attacks of encephalitis with neuritic or, more frequently, poliomyelitic symptoms. It is often followed by some mental reduction.

These various forms may give rise to secondary psychopathic changes, especially in children. These have shown, for scveral months after their attacks, lack of interest, difficulty in memorizing, and general inaptitude with lessons. In addition to this there is a permanent change in character and temperament. The prognosis is not good in such cases.

Too little is known of the pathological anatomy and of the bacteriology of these conditions to allow of a clear interpretation of the cases. At present it is only possible to speculate as to where the primary trouble is -whether the disorder is in the brain itself, or if it is secondary to some pathological change elsewhere in the body which reacts upon the brain.

Hubert J. Normas.

\section{TREATMENT.}

[149] Some aspects of mental hygiene.-E. Farquiar BIzzard. Proc. Roy. Soc. Med., 1921, xiv, 1.

Tue writer includes under the term of mental hygiene all measures which aim at the prevention of mental disorders, whether they are in the nature of neuroses, psychoneuroses, or psychoses. Its growth must be promoted : (1) By no longer misnaming mental disorders as nervous. It is necessary to tell the patients that their symptoms are mental and that these disorders are of everyday occurrence. (2) By getting rid of the confusion between ethical and medical principles as they affect health. (3) By teaching clementary principles of psychopathology and psychotherapy to students so that the general practitioner may take a prominent part in maintaining the mental health of individuals. He alone is able to detect which child in a family is finding difficulty in adaptation to the realities of life, or whether a threatening neurosis or psychosis is duc more to inherent defects in the child or to external causes. (4) By obtaining gencral recognition for the multiplicity of factors concerned in producing mental as well as other disorders. The condition of the teeth, the lower bowel, the duetless glands, etc., may play a part in the production of mental disorder as well as the inherent constitutional factor and mental conflicts. (5) By giving duc prominence to fatigue as a factor in psychopathology and to rest in psychotherapy. (6) By encouraging education in thinking as an important preventive measure.

The importance of psycho-analysis and other psychotherapcutic measures in the understanding prevention, and treatment of mental disorders is emphasized.

C. IV. Forsyth.

[150] Recreation for mental cases.-R. F. L. Ridgway. Amer. Jour. Psychiat., 1921, i, 87.

'THE main object of recreation is to divert the mind of the patient from any morbid thoughts, feclings, or habits into more healthful channels, so that his life, as a whole, may be influeneed beneficially. The forms of recreation may be said to fall roughly into two classes, those in which there 